Editorial

\title{
The Future of REM: Perspectives of the Incoming Editor-in-Chief
}

It is a distinct privilege to serve as Editor-in-Chief of Rangeland Ecology and Management (REM). I greatly appreciate the confidence that has been bestowed upon me with my appointment to this important position. The Journal represents the scientific foundation of our professional Society, and recently implemented changes to the Journal have placed it on a positive trajectory. My intent is to build upon the momentum created by the former Editor-in-Chief Keith Owens, the Editorial Board, and numerous others that have contributed to the Journal's success during the past several years. The Society owes Keith Owens a huge debt of gratitude for his exceptional service in skillfully guiding the Journal through its transition to electronic manuscript submission and review and publication by Allen Press.

My perception of the mission of REM is to foster communication of science-based information to promote wise stewardship of global rangelands. This mission is most effectively addressed by capitalizing on the inherent strength of $R E M$ to integrate multidisciplinary information to inform academics, policy makers, and natural resource managers of the numerous challenges and opportunities confronting rangelands. This will require that the subject matters areas of ecology, management, socioeconomics, and policy continue to be represented in subsequent issues of REM.

The primary goal during my four-year term will be to elevate REM to the next tier of academic journals while continuing to publish manuscripts addressing all aspects of global rangeland resources. This goal will be addressed by emphasizing three specific objectives. First, maintain the size, scope, and diversity of the Editorial Board with recognized scientists and scholars from varied disciplines and nationalities. This will continue to promote the national and international profile of REM. Second, further increase the efficiency of manuscript review to reduce turnaround time from submission to receipt of an editorial decision. Turnaround time has become an important metric in author selection of science journals and REM must strive to remain competitive. Third, continue to increase the number, quality, and scope of manuscript submissions, both nationally and internationally, by soliciting a greater number of high-profile synthesis, forum, and special-feature papers (see REM Style Manual for additional information regarding manuscript categories). Special Feature Associate Editors will be appointed to the Editorial Board with the sole purpose of soliciting and reviewing these categories of manuscripts.

The positive trajectory that REM currently enjoys has partially resulted from our partnership with Allen Press to publish and market the Journal. Increased production quality, on-line submission and review, and aggressive electronic distribution have greatly increased the Journal's profile and impact. Allen Press has developed and recently implemented several additional improvements that will further promote REM. A summary of these modifications is presented below.

1. A separate REM home page is being developed to provide increased visibility and access to a greater amount of relevant information at a single site.

2. Manuscripts will be electronically prepublished on this site immediately following acceptance.

3. REM has been bundled into two additional electronic journal aggregations that will promote readership in Europe and deliver translated content to 400 Chinese universities.

4. The electronic manuscript review system operated by Allen Press (AllenTrack) has been modified to increase efficiency and clarity for both authors and reviewers. This includes a figure-verification feature that enables authors to evaluate the quality of figures and tables prior to submission of an accepted manuscript.

5. Volumes 1-57 of REM and its predecessor (Journal of Range Management) have been archived on JSTOR for increased access. Members can access the files at www.jstor.org and individual papers can be purchased via pay-per-view.

6. REM will be printed on paper certified by the Forest Stewardship Council to promote environmental awareness of both our Society and Allen Press.

We are fortunate to have Allen Press as a partner to direct us through this time of rapid change in the publication industry. Current changes include a large shift from print to on-line publication, decreased library subscriptions, and increased access of individual titles through Web-based search engines. It is clear that further change is eminent and we must be willing to anticipate and adapt to these new conditions to enable REM to develop into an academic clearinghouse for global rangeland issues.

This is a challenging and exciting time for global rangelands. I look forward to working with the Editorial Board, the Society, Allen Press, and authors within the global rangeland community to ensure that REM plays a pivotal role in addressing these challenges to promote effective rangeland stewardship.

David D. Briske, Editor-in-Chief of Rangeland Ecology \& Management, Ecosystem Science and Management, Texas AoM University, College Station, TX, USA 